\title{
Kawasaki disease in a northern region of Italy
}

\author{
Elena Corinaldesi ${ }^{* *}$, MFabi $^{2}$, G Savorelli ${ }^{2}$ \\ From 18th Pediatric Rheumatology European Society (PReS) Congress \\ Bruges, Belgium. 14-18 September 2011
}

\section{Objective}

To examine the patient characteristics, diagnostic criteria, treatment, complications and outcomes of Kawasaki disease (KD) in a cohort of patients of two pediatric hospitals of Emilia Romagna from 2000 to 2010.

\section{Methods}

Retrospective study: 26 patients diagnosed with complete or incomplete KD. Clinical and outpatient statuses were collected.

\section{Results}

Male-to-female ratio was 1 to 1 . Median age at onset: 35,8 months (2-101 months); children $<6$ months: $23 \%$. Complete KD: $73 \%$. Age was not significant different between complete and incomplete KD.

Season of Onset of disease : winter in 35\%, spring $31 \%$, summer $11 \%$, autumn $23 \%$. Diagnostic signs: iperemic conjunctivitis and mucositis in $92 \%$ of pts, cutaneous rash in $88 \%$, linfoadenopathy in $54 \%$, alterations of extremities in $50 \%$, desquamation of extremities in $58 \%$; adjunctive signs: perineal dermatitis in $30 \%$ and diarrhea in $42 \%$.

7 pts (5 boys) developed coronary involvement (group1): markers of inflammation and age at onset were not significantly different between group 1 and group 2 (without cardiac abnormalities). $28 \%$ of pts in group 1 was responder to therapy versus $47 \%$ in group 2. Coronary involvement regressed in all but 2 pts (both received late treatment).

\section{Conclusions}

Male gender and late start of treatment were shown to be independent risk factors for developing coronary involvement, while younger age and incomplete form were not.

\footnotetext{
* Correspondence: elcorinaldesi@yahoo.it

${ }^{1}$ Department of Pediatry, Carpi, Italy

Full list of author information is available at the end of the article
}

Late intravenous immunoglobulins seems to be risk factor for persistence of coronary aneurysm, but the small number of patients limits us to have definite conclusions .

\section{Author details}

${ }^{1}$ Department of Pediatry, Carpi, Italy. ${ }^{2}$ Department of Pediatry, Bologna, Italy.

Published: 14 September 2011

doi:10.1186/1546-0096-9-S1-P81

Cite this article as: Corinaldesi et al:: Kawasaki disease in a northern region of Italy. Pediatric Rheumatology 2011 9(Suppl 1):P81.

Submit your next manuscript to BioMed Central and take full advantage of:

- Convenient online submission

- Thorough peer review

- No space constraints or color figure charges

- Immediate publication on acceptance

- Inclusion in PubMed, CAS, Scopus and Google Scholar

- Research which is freely available for redistribution 